\title{
Creep Behaviour of Fly Ash-Based Geopolymer Concrete
}

\author{
Wallah, S.E. ${ }^{1)}$
}

\begin{abstract}
Fly ash-based geopolymer concrete is manufactured using fly ash as its source material and does not use Portland cement at all. Beside fly ash, alkaline solution is also utilized to make geopolymer paste which binds the aggregates to form geopolymer concrete. This paper presents the study of creep behaviour of fly ash-based geopolymer concrete. Four series of specimens with various compressive strengths were prepared to study its creep behaviour for the duration of test up to one year. The test method followed the procedures applied for Ordinary Portland Cement (OPC) concrete. Test results show that fly ash-based geopolymer concrete undergoes low creep which is generally less than that of OPC concrete. After one year of loading, the results for specific creep of fly ash-based geopolymer concrete in this study ranges from 15 to 29 microstrain for concrete compressive strength 67-40 MPa respectively. From the test results, it is also found out that the creep coefficient of fly ash-based geopolymer concrete is about half of that predicted using Gilbert's Method for OPC concrete.
\end{abstract}

Keywords: creep, fly ash, geopolymer concrete.

\section{Introduction}

The production of Portland cement, a main component of making concrete, contributes significant amount of greenhouse gas, because the production of one ton of Portland cement also releases about one ton of carbon dioxide gas into the atmosphere [1]. Therefore, the introduction of a novel binder called 'geopolymer' by Davidovits [2,3] promises a good prospect for application in the concrete industry as an alternative binder to Portland cement. In terms of reducing global warming, the geopolymer technology could reduce the $\mathrm{CO}_{2}$ emission to the atmosphere caused by cement and aggregates industries by $80 \%$ [4].

Inspired by this novel technology and the fact that fly ash is a waste material abundantly available, an attempt has been made to develop an alternative concrete binder by applying the geopolymer technology and utilising fly ash as the source material to produce the Fly Ash-Based Geopolymer Concrete. Hardjito, et. al. [5] introduced the early work on fly ash-based geopolymer concrete dealing with the manufacturing process and the effect of curing period, curing temperature and the age of concrete on the compressive strength of fly ash-based geopolymer concrete.

\footnotetext{
${ }^{1}$ Faculty of Engineering, Sam Ratulangi University, Indonesia Email:wsteenie@yahoo.com
}

Note: Discussion is expected before November, $1^{\text {st }} 2010$, and will be published in the "Civil Engineering Dimension" volume 13, number 1, March 2011.

Received 21 May 2009; revised 6 December 2009; accepted 26 January 2010.
Moreover, the effect of alkaline ratio and the ratio of alkaline to water was also studied. More research results on the factors affecting the compressive strength and other properties of fresh and hardened fly ash-based geopolymer concrete were also reported [6-9]. Attempts to apply this material as a structural material have been carried out by studying the behaviour and strength of reinforced fly ash-based geopolymer concrete beams and columns [10,11] This paper presents the study on fly ash-based geopolymer concrete, focused on its creep behaviour, an important long-term property of concrete as a structure material.

\section{Creep of Concrete}

Creep is time dependent increase in strain of hardened concrete under sustained stress. Under normal condition of loading, the instantaneous strain at the application of load includes not only the elastic strain but also some creep. However, normally creep is simply taken as the increase in strain above the initial elastic strain [12]. In a loaded condition, a specimen also undergoes shrinkage as it dries, therefore this fact should be accounted for in calculating the actual creep. For practical simplification, creep might be calculated as the difference between total time deformation and shrinkage of a similar unloaded specimen stored under the same conditions through the same period.

Creep is usually determined by measuring the change, with time, in the strain of specimens subjected to a constant stress and stored under appropriate conditions. Australian Standard [13] outlines a method of determining the creep of 
concrete cylinders in compression which was used as the basis to determine the creep in this work.

\section{Fly Ash-Based Geopolymer Concrete}

Geopolymer concrete is manufactured using source materials that are rich in silica and alumina. While the cement-based concrete utilises the formation of calcium-silica hydrates (CSHs) for matrix formation and strength, geopolymers involve the chemical reaction of alumino-silicate oxides with alkali polysilicates yielding polymeric $\mathrm{Si}-\mathrm{O}-\mathrm{Al}$ bonds $[14,15]$. In geopolymer concrete, the silica and the alumina present in the source materials are first induced by alkaline activators to form a gel. This geopolymer gel binds the loose aggregates and other inert materials in the mixture to form the geopolymer concrete. In this experimental work, fly ash is used as the source material to make geopolymer paste as the binder, to produce concrete. The manufacture of geopolymer concrete is carried out using the usual concrete technology methods. As in the Portland cement concrete, in fly ash-based geopolymer concrete, the aggregates occupy the largest volume, i.e. about $75-80 \%$ by mass. The silicon and the aluminium in the fly ash are activated by a combination of sodium hydroxide and sodium silicate solutions.

\section{Materials and Mixture Proportions}

Geopolymer concrete in this study utilised the low calcium (class F) fly ash from Collie Power Station, Western Australia as the source material. Table 1 shows the chemical composition of the fly ash as determined by X-Ray Fluorescence (XRF) analysis. It can be seen from Table 1, the silicon and aluminium oxides constitute about $80 \%$ of the fly ash and the Sito-Al ratio is about two. Particle size analysis is presented in Fig. 1. Graph A shows the percentage of the volume passing and Graph B shows the percentage volume for certain sizes

Aggregates, comprising $20 \mathrm{~mm}, 14 \mathrm{~mm}$ and $7 \mathrm{~mm}$ coarse aggregates and fine aggregate in saturated surface dry conditions, were used. The coarse aggregates were crushed granite-type aggregates and the fine aggregate was fine sand.

The alkaline activator was a combination of analytical grade sodium hydroxide $(\mathrm{NaOH})$ in flake form with $98 \%$ purity dissolved in water and sodium silicate $\left(\mathrm{Na}_{2} \mathrm{O}=14.7 \%, \mathrm{SiO}_{2}=29.4 \%\right.$, and water $=$ $55.9 \%$ by mass solution).

In order to improve the workability, a high range water-reducing admixture with a dosage of $1.5 \%$ by mass of the fly ash was added to the mixture.
Table 1. Chemical composition of fly ash (\% by mass)

\begin{tabular}{cc}
\hline $\mathrm{SiO}_{2}$ & 47.80 \\
$\mathrm{Al}_{2} \mathrm{O}_{3}$ & 24.40 \\
$\mathrm{Fe}_{2} \mathrm{O}_{3}$ & 17.40 \\
$\mathrm{CaO}$ & 2.42 \\
$\mathrm{Na}_{2} \mathrm{O}$ & 0.31 \\
$\mathrm{~K}_{2} \mathrm{O}$ & 0.55 \\
$\mathrm{TiO}_{2}$ & 1.328 \\
$\mathrm{MgO}$ & 1.19 \\
$\mathrm{P}_{2}$ & 2.00 \\
$\mathrm{SO}$ & 0.29 \\
$\mathrm{Cr}$ & 0.01 \\
$\mathrm{MnO}$ & 0.12 \\
$\mathrm{LOI}^{*}$ & 1.10 \\
\hline
\end{tabular}

*Loss on ignition

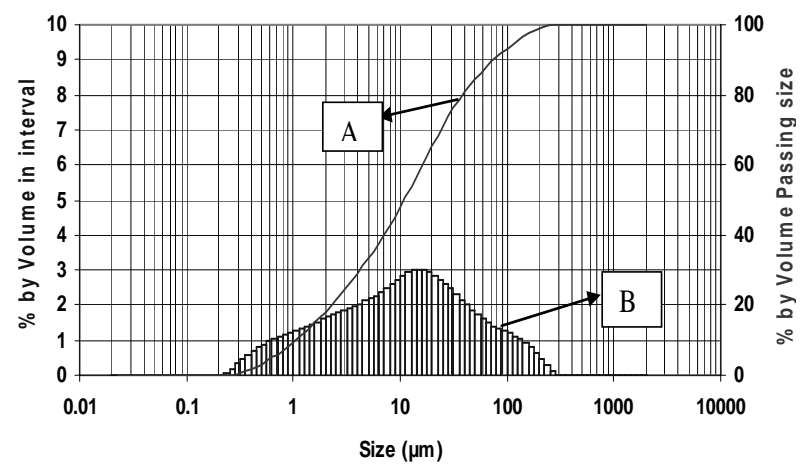

Figure 1. Particle size distribution of fly ash

Two types of mixture were used to make fly ashbased geopolymer concrete as shown in Table 2 .

Table 2. Mixture Proportions for Fly Ash-Based Geopolymer Concrete

\begin{tabular}{lcc}
\hline \multicolumn{1}{c}{ Materials } & \multicolumn{2}{c}{ Mass $\left(\mathbf{k g} / \mathbf{m}^{3}\right)$} \\
\cline { 2 - 3 } & Mixture-1 & Mixture-2 \\
\hline Coarse Aggregate & 1294 & 1294 \\
Fine sand & 554 & 554 \\
Fly ash (low-calcium ASTM & 408 & 408 \\
Class F) & & \\
Sodium silicate solution & 103 & 103 \\
(SiO $\left./ \mathrm{Na}_{2} \mathrm{O}=2\right)$ & & \\
Sodium hydroxide solution & $41(8 \mathrm{M})$ & $41(14 \mathrm{M})$ \\
Super Plasticiser & 6 & 6 \\
Extra water & 0 & 22.5 \\
\hline
\end{tabular}

\section{Manufacture}

The sodium hydroxide flakes were dissolved in distilled water to make a solution with a desired concentration at least one day prior to use. The fly ash and the aggregates were first mixed together in a pan mixer for about three minutes. The sodium hydroxide and the sodium silicate solutions were mixed together with superplasticizer and the extra water and then added to the dry materials and mixed for about four minutes. The fresh concrete was 
cast into the molds immediately after mixing, in three layers and compacted with manual strokes and vibrating table. After casting, the specimens were cured at $60^{\circ} \mathrm{C}$ for 24 hours. Two types of curing were applied, dry curing and steam curing. For dry curing, the specimens were cured in an oven and for steam curing the specimens were cured in the steam curing chamber. After curing, the specimens were left to air-dry in the laboratory for the next six days until testing on the $7^{\text {th }}$ day.

\section{Experimental Procedures}

For each test category, eight 150 x 300 mm cylinder specimens were made. Three of these cylinders were used for the creep test (Fig. 2), and two were used as companion specimens to measure the drying shrinkage. The other three cylinders were utilised for compressive strength tests. After curing, the test specimens were demolded and stored at room temperature in the laboratory. Tests commenced on the $7^{\text {th }}$ day after casting. The test procedures followed the relevant Australian Standard for determination of creep of concrete cylinders in compression [13]. The strains were measured using demec gauge measuring device with demec targets fixed on the specimens.

Four series of specimens were prepared from two types of mixture proportion and two types of heat curing (dry curing or steam curing) were applied for each type of mixture (Table 3).

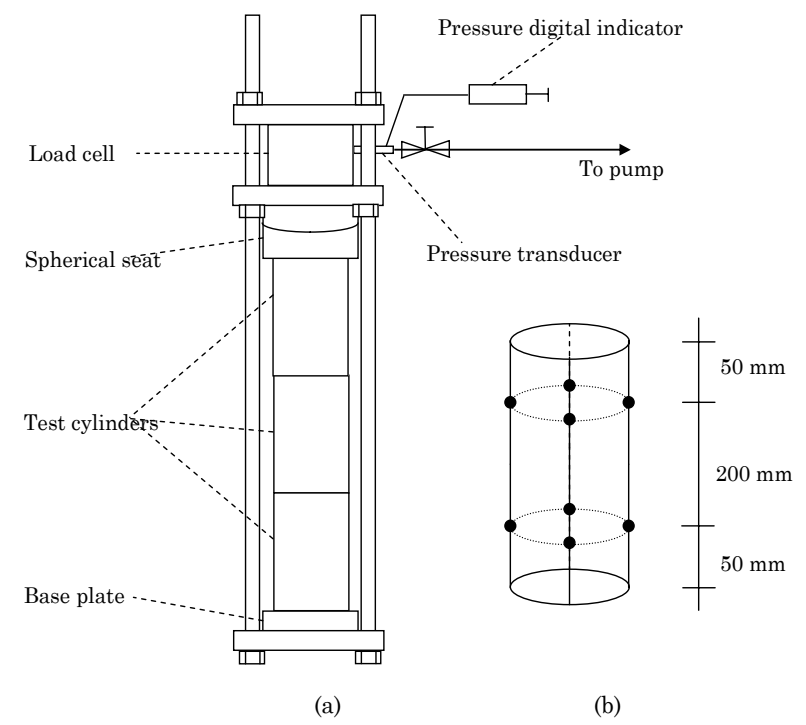

Figure 2. (a) Creep Test Set-up (b) Location of Demec Gauge Points on Test Cylinders

As shown in Fig. 2, the three specimens for creep test were placed in a specially-built creep testing frame with a hydraulic loading system. Before the creep specimens were loaded, the $7^{\text {th }}$ day compressive strength of geopolymer concrete was determined by testing the three cylinders reserved for the compressive strength test. The creep specimens were applied with a load corresponding to 40 percent of the measured mean compressive strength of concrete. This load was maintained as the sustained load throughout the duration of the test. The strain values were measured and recorded immediately before and after the loading. Strains suffered by the control shrinkage specimens were measured at the same time as the strain measurements on creep specimens. The strain values were measured and recorded at two hours, six hours and then every day for the first week, after loading. The measurements then continued once a week until the fourth week. After that, the measurements were done once in two weeks until the twelfth week and then once every four weeks until one year.

Table 3. Series of Creep Test

\begin{tabular}{cll}
\hline Test Designation & Mixture & Curing type \\
\hline 1CR & Mixture-1 & Dry \\
2CR & Mixture-1 & Steam \\
3CR & Mixture-2 & Dry \\
4CR & Mixture-2 & Steam \\
\hline
\end{tabular}

\section{Results and Discussions}

The average compressive strength for Mixture-1 was $67 \mathrm{MPa}$ for the specimens cured in the oven (1CR) and $57 \mathrm{MPa}$ for the specimens cured in the steamcuring chamber (2CR). For Mixture-2, these values were $47 \mathrm{MPa}$ and $40 \mathrm{MPa}$, respectively.

Table 4 presents the $7^{\text {th }}$ day compressive strength and the applied sustained stress of creep specimens.

Table 4. Compressive Strength and Sustained Stress of Creep Specimens

\begin{tabular}{ccc}
\hline Test Designation & $\begin{array}{c}\mathbf{7}^{\text {th }} \text { Day compressive } \\
\text { strength (MPa) }\end{array}$ & $\begin{array}{c}\text { Sustained stress } \\
\text { (MPa) }\end{array}$ \\
\hline 1CR & 67 & 27 \\
2CR & 57 & 23 \\
3CR & 47 & 19 \\
$4 \mathrm{CR}$ & 40 & 16 \\
\hline
\end{tabular}

Table 5 gives the sustained stress and the instantaneous strain measured immediately after the application of the sustained load. Using these data, the instantaneous elastic modulus was calculated as sustained stress divided by instantaneous strain. The values of instantaneous elastic modulus, given in Table 5, are similar to those reported earlier for fly ash-based geopolymer concrete [16].

Figure 3 presents the creep strain (after subtracting the drying shrinkage strain from total strain) measured for a period of 52 weeks (one year). The total strain was measured on the specimens in the 
creep test rig, while the drying shrinkage strain was obtained from the companion unloaded specimens left in the vicinity of the creep specimens. The creep strain in those figures includes the instantaneous elastic strain. The creep coefficient, taken as the ratio of the creep strain to the instantaneous strain is shown in Figure 4.

Table 5. Instantaneous Strain and Instantaneous Elastic Modulus

\begin{tabular}{cccc}
\hline $\begin{array}{c}\text { Test } \\
\text { Designation }\end{array}$ & $\begin{array}{c}\text { Sustained } \\
\text { stress } \\
\text { (MPa) }\end{array}$ & $\begin{array}{c}\text { Instantaneous } \\
\text { strain } \\
\text { (microstrain) }\end{array}$ & $\begin{array}{c}\text { Instantaneous } \\
\text { Elastic Modulus } \\
\text { (MPa) }\end{array}$ \\
\hline 1CR & 27 & 902 & 29574 \\
2CR & 23 & 851 & 26852 \\
3CR & 19 & 828 & 22913 \\
4CR & 16 & 761 & 21144 \\
\hline
\end{tabular}

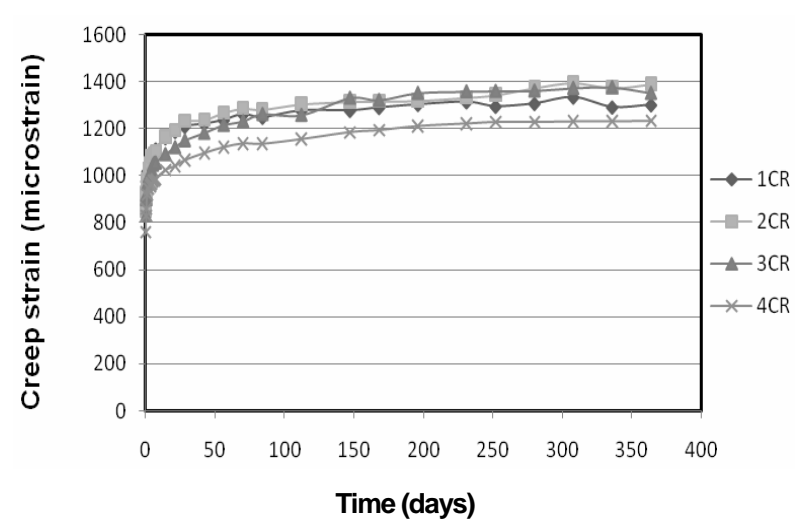

Figure 3. Creep Strain

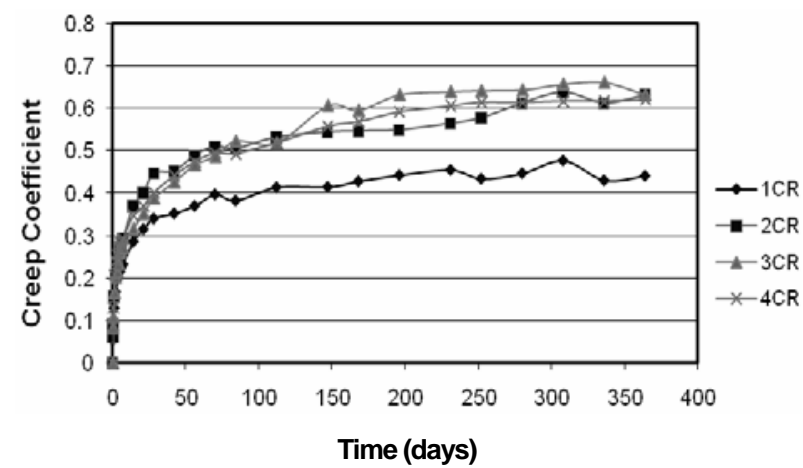

Figure 4. Creep Coefficient

The specific creep, defined as the creep strain per unit stress, for all test categories are presented in Figure 5.

The test results presented in Figure 3 and Figure 4 show that the creep data fluctuated slightly over the period of sustained loading. This might be due to the variations in the relative humidity of the laboratory room where the creep test rig was housed.

The effect of concrete compressive strength on the creep of fly ash-based geopolymer concrete is illustrated in Figure 5. The test data show that the specific creep decreased as the compressive strength increased. This test trend is similar to that observed in the case of OPC concrete as reported by Neville et al. [17], Gilbert [18] and Warner et al. [19].

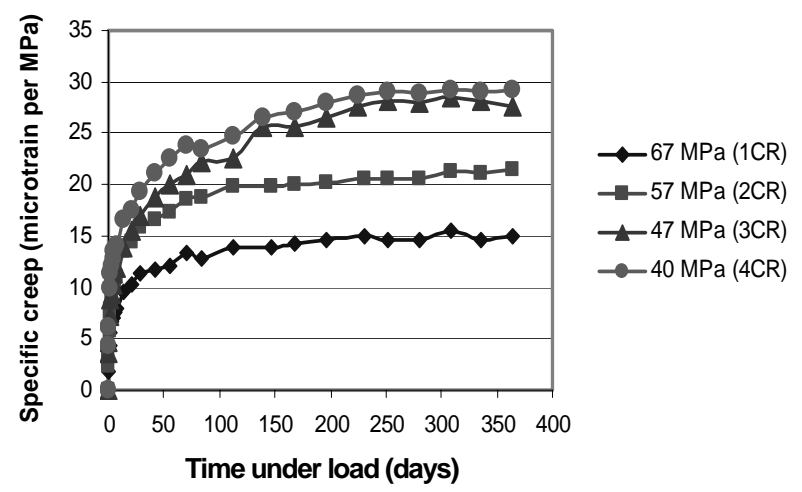

Figure 5. Specific Creep of Fly Ash-Based Geopolymer Concrete

The final values of specific creep of fly ash-based geopolymer concrete after one year of loading are summarised in Table 6 . It can be seen that the final specific creep values increase in the decreasing rate with the decrease in compressive strength. The rate of increase in specific creep shows relatively similar trend for concrete compressive strength 67,57 , and $47 \mathrm{MPa}$ (1CR, 2CR and 3CR). However, that value for $4 \mathrm{CR}$ (40 MPa concrete) is smaller compared to the trend for other categories. If the decreasing rate is assumed to be linear, the specific creep for $40 \mathrm{MPa}$ concrete (4CR) should be around 31.5 microstrain/ $\mathrm{MPa}$ compared to 29 microstrain/MPa from test results. This might be caused by the slight variation in the test results as discussed previously, or this results suggest that the rate of change in specific creep of fly ash-based geopolymer concrete is much lower for low compressive strength. However, it still needs to be confirmed by studying the creep behaviour of fly ash-based geopolymer concretes with lower compressive strength than those observed in this study.

Table 6. Final Specific Creep of Geopolymer Concrete after one-year Loading

\begin{tabular}{ccc}
\hline Designation & $\begin{array}{c}\text { Compressive } \\
\text { strength } \\
\text { (MPa) }\end{array}$ & $\begin{array}{c}\text { Final specific creep after one } \\
\text { year loading (x10-6/MPa) }\end{array}$ \\
\hline 1CR & 67 & 15 \\
2CR & 57 & 22 \\
3CR & 47 & 28 \\
4CR & 40 & 29 \\
\hline
\end{tabular}

The test results generally indicate that fly ash-based geopolymer undergoes less creep compared to OPC concrete. Warner et. al. [19] illustrated that for OPC concrete the specific creep for $60 \mathrm{MPa}$ concrete after one year was about 50 to 60 microstrain/MPa, while this value after six months was about 30 to 40 microstrain/MPa for $80 \mathrm{MPa}$ concrete and about 20 to 30 microstrain/MPa for $90 \mathrm{MPa}$ concrete. 
Similarly, Malhotra and Mehta [20] reported that the specific creep of high-performance high volume fly ash (HVFA) concrete was about 24 to 32 microstrain/MPa after one year under loading. Those values are generally higher than the values given in Figure 5 and Table 6 for fly ash-based geopolymer concrete. This fact becomes more obvious when the creep data of geopolymer concrete are compared with the values predicted by using Gilbert's method [21] for OPC concrete as proposed in the draft Australian Standard for Concrete Structures AS3600, in which the test results are significantly smaller about 50\% from the predicted values.

The creep strains of fly ash-based geopolymer concrete are generally smaller than that of OPC concrete. The exact reasons for this difference in behaviour are not known yet. However, it has been suggested by Davidovits [22] that the smaller creep strains of fly ash-based geopolymer concrete may be explained by the 'block-polymerisation' concept. According to this concept, the silicon and aluminium atoms in the fly ash are not entirely dissolved by the alkaline liquid. The 'polymerisation' that takes place only on the surface of the atoms is sufficient to form the 'blocks' necessary to produce the geopolymer binder. Therefore, the insides of the atoms are not destroyed and remain stable, so that they can act as 'micro-aggregates' in the system.

In OPC concrete, the creep is primarily caused by the cement paste. The aggregates are generally inert component of the mixtures, and function to resist the creep of the cement paste. Therefore, the aggregate content in the concrete is a significant factor influencing the creep of the concrete as the creep will decrease with the increase in the quantity of the aggregates. The proportion of aggregates in the mixtures of fly ash-based geopolymer concrete used in this work is approximately similar to that used in OPC concrete. However, the presence of the 'microaggregates' due to the 'block-polymerisation' mentioned above gives the effect of increasing the aggregate content in the concrete. In other words, the presence of the 'micro-aggregates' increases the creep resisting function of the fly ash-based geopolymer concrete which results in smaller creep compared to OPC concrete without 'micro-aggregates'.

\section{Conclusions}

This paper presented the study of creep behaviour of fly ash-based geopolymer concrete manufactured using fly ash as its source material, alkaline liquid and aggregates as normally used for Ordinary Portland Cement (OPC) concrete. This concrete was heat cured at $60^{\circ} \mathrm{C}$ for 24 hours. From test results, it is concluded that fly ash-based geopolymer concrete undergoes low creep. The specific creep after one year loading ranges from 15 to $29 \times 10^{-6 /} \mathrm{MPa}$ for the corresponding compressive strength of 67 to $40 \mathrm{MPa}$. As in Ordinary Portland Cement (OPC) concrete, specific creep of fly ash-based geopolymer concrete decreases as the compressive strength increases. The creep coefficient after one year of loading for fly ashbased geopolymer concrete with compressive strength of 40,47 , and $57 \mathrm{MPa}$ is around 0.6 to 0.7 , while for geopolymer concrete with compressive strength of $67 \mathrm{MPa}$ this value is around 0.4 to 0.5 . These values are about $50 \%$ of the values predicted by Gilbert method as proposed in the draft Australian Standard for Concrete Structures AS3600 for OPC concrete.

\section{References}

1. McCaffrey, R., Climate Change and the Cement Industry, Global Cement and Lime Magazine (Environmental Special Issue), 2002, pp. 15-19.

2. Davidovits, J., Geopolymer Chemistry and Properties. Proceedings of Geopolymer '88, First European Conference on Soft Mineralurgy, The Geopolymer Institute, Compiegne, France, 1988, pp. 25-48.

3. Davidovits, J., Soft Mineralurgy and Geopolymers, Proceedings of Geopolymer '88, First European Conference on Soft Mineralurgy, The Geopolymer Institute. Compiegne, France, 1988, pp. 19-24.

4. Davidovits, J., Global Warming Impact on the Cement and Aggregates Industries, World Resource Review, 6(2), 1994, pp. 263-278.

5. Hardjito, D., Wallah S.E., and Rangan B.V., Study on Engineering Properties of Fly AshBased Geopolymer Concrete, Journal of the Australasian Ceramic Society, 38(1), 2002, pp. 4447.

6. Hardjito, D., Wallah, S. E., Sumajouw, D.M.J., and Rangan, B.V., Factors influencing the Compressive Strength of Fly Ash-Based Geopolymer Concrete, Civil Engineering Dimension (Dimensi Teknik Sipil), 6(2), 2004, pp. 88-93.

7. Hardjito, D., Wallah, S.E., Sumajouw, D.M.J., and Rangan, B.V., On the Development of Fly Ash-Based Geopolymer Concrete, ACI Materials Journal, 101(6), 2004, pp. 467-472.

8. Wallah, S.E., Hardjito, D., Sumajouw, D.M.J., and Rangan. B.V., Geopolymer Concrete: A Key for Better Long-Term Performance and Durability. Proceedings of ICFRC, International Conference on Fibre Composites, High Performance Concretes and Smart Materials. Chennai, India, 2004, pp. 527-539. 
9. Hardjito, D., Wallah, S.E., Sumajouw, D.M.J., and Rangan, B.V., Fly Ash-Based Geopolymer Concrete, Australian Journal of Structural Engineering, 6(1), 2005, pp. 77-86.

10. Sumajouw, D.M.J., Hardjito, D., Wallah, S.E., and Rangan, B.V., Behaviour and Strength of Geopolymer Concrete Columns, $18^{\text {th }}$ Australasian Conference on the Mechanics of Structures and Materials, Perth, Australia: A.A. Balkema, Vol 1, 2004, pp. 175-180.

11. Sumajouw, D.M.J., Hardjito, D., Wallah, S., and Rangan, B.V., Flexural Behaviour of Reinforced Fly Ash-Based Geopolymer Concrete Beams. Concrete 05, CIA 22 nd Biennial Conference, Concrete Institute of Australia, Melbourne, Australia, 2005.

12. Neville, A.M., Properties of Concrete, Fourth and Final ed, Pearson Education, Longman Group Essex, England, 2000.

13. Standards-Australia, Methods of Testing Concrete Determination of Creep of Concrete Cylinders in Compression, AS 1012.16-1996.

14. Davidovits, J., Geopolymers: Inorganic Polymeric New Materials, Journal of Thermal Analysis, 37, 1991, pp. 1633-1656.

15. van Jaarsveld, J.G.S., van Deventer, J.S.J., and Lukey, G.C., The Effect of Composition and Temperature on the Properties of Fly Ash and Kaolinite-Based Geopolymers, Chemical Engineering Journal, 89(1-3), 2002, pp. 63-73.
16. Hardjito, D., Wallah, S.E., Sumajouw, D.M.J., and Rangan, B.V., The Stress-Strain Behaviour of Fly Ash-Based Geopolymer Concrete, in Development in Mechanics of Structures and Materials, A.J. Decks and H. Hao, Editors, A.A. Balkema Publishers: Leiden, 2004, pp. 831-834.

17. Neville, A.M., Dilger, W.H., and Brooks, J.J., Creep of Plain and Structural Concrete, Construction Press, Longman Group London, 1983.

18. Gilbert, R.I., Time Effects in Concrete Structures, Elsevier Amsterdam, 1988.

19. Warner, R.F., Rangan, B.V., Hall, A.S., and Faulkes, K.A., Concrete Structures, Longman Melbourne, 1998.

20.Malhotra, V.M. and Mehta, P.K., HighPerformance, High-Volume Fly Ash Concrete: Materials, Mixture Proportioning, Properties, Construction Practice, and Case Histories, Supplementary Cementing Materials for Sustainable Development Inc. Ottawa, 2002.

21.Gilbert, R.I., Creep and Shrinkage Models for High Strength Concrete-Proposal for Inclusion in AS3600, Australian Journal of Structural Engineering, 4(2), 2002, pp. 95-106.

22.Davidovits, J., Personal Communication on Geopolymer Chemistry. 2005. 